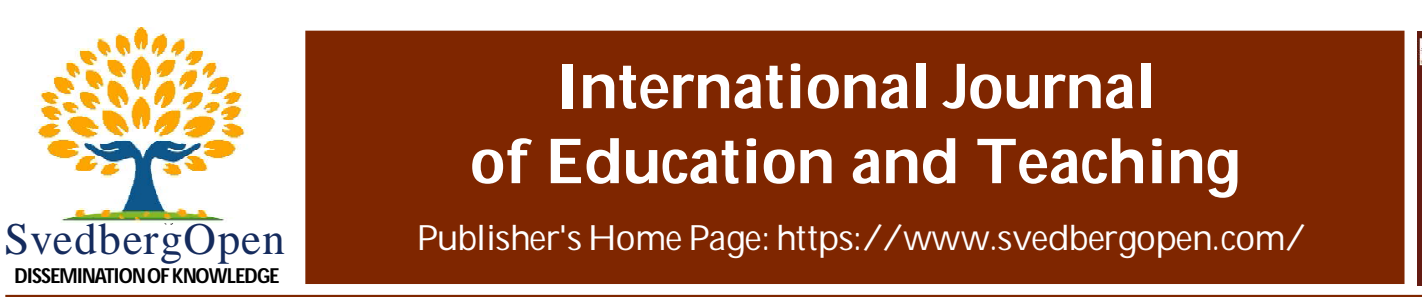

Review Article

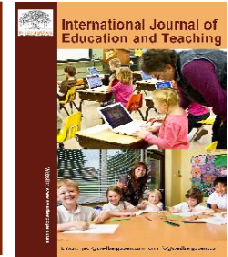

\title{
Philosophy on Educational Accessibility: An Opportunity and Societal Privileges
}

\author{
Noel P. Sobejana ${ }^{*}$ \\ 'Davao Del Sur State College, Digos City, Davao del Sur, Philippines. E-mail: noel.sobejana@dssc.edu.ph
}

\section{Article Info}

Volume 1, Issue 3, September 2021

Received : 19 January 2021

Accepted : 17 August 2021

Published : 05 September 2021

doi: 10.51483/IJEDT.1.3.2021.1-6

\begin{abstract}
This is an essay from the philosophical point of view in terms of asking on a situation on the agenda of having the privilege or just simply an opportunity an education in the Philippines based on a review of literature. It is an opportunity as it is basically a right and may be a privilege of a human being in the appreciation of life and an opportunity that is communicate in a structured government that envisions to have a stable direction. The review is guided with the following questions that are as follows; (1) what education is best to community opportunity and societal privilege; (2) what is the best educational schema that can be applied in building of an academic institution that envisions economic sustainability; (3) what are the characteristics of an educational system as anchored with the philosophy of education; and (4) what educational structure or paradigm to be best suit societal opportunity and privilege? The method is purely the extensive and careful selection of statements that contributes to theoretical implication. Thus, the result provided a most challenging moments to the community and it is up to the new generation to accept that education is neither an opportunity nor a privilege.
\end{abstract}

Keywords: Philosophy, Education accessibility, Philippines, Opportunity, Privilege

(C) 2021 Noel P. Sobejana. This is an open access article under the CC BY license (https://creativecommons.org/licenses/by/4.0/), which permits unrestricted use, distribution, and reproduction in any medium, provided you give appropriate credit to the original author(s) and the source, provide a link to the Creative Commons license, and indicate if changes were made.

\section{Introduction}

Education is an opportunity as it is basically a right and may be a privilege of a human being in the appreciation of life. An opportunity that is communicate in a structured government that envisions to have a stable direction. That, a member of a community has the right to be educated to appreciate about the true meaning of life. Thus, education in the context of a just government aiming for a successful community is a rightful scheme in building a nation.

The contributing factors in the educational governance to have a specific improvement are specified with various indicators. These indicators are being classified through its use and importance. Thus, this gathered statement from a point of view of a researcher that points out education is a necessity of every individual to learn and develop specific skills. Though, it is stressed that education is one of the indicators of societal development but still it is a challenge because of some circumstances that learning depends to satisfy one's personal interest. Thus, this essay illustrates and discusses the new meaning of education as an opportunity and a privilege.

Education promotes equality lifts people out of poverty. It teaches children how to become good citizens. Education is not just for a privileged few, it is for everyone. It is a fundamental human right.

\footnotetext{
* Corresponding author: Noel P. Sobejana, Davao Del Sur State College, Digos City, Davao del Sur, Philippines.

E-mail: noel.sobejana@dssc.edu.ph
}

2788-5011/@ 2021. Noel P. Sobejana. This is an open access article distributed under the Creative Commons Attribution License, which permits unrestricted use, distribution, and reproduction in any medium, provided the original work is properly cited. 
The specific objectives of this essay focused on implementation as propelled with appropriate strategy in running an educational institutional for the country. Enumerating and gathering of articles from different books, journals, published and unpublished researches are composites of the strategies presented in this article. This is in the way of collecting same of the facts on education that explains its easy accessibility as a result of a successful community and governance. This is a compendium of various statement of authors with their common beliefs on the true essence of education bringing in clear evidence of success while there are still to be found to give light on what course of action the government should take. Generalization may or may not be applicable but adoption and implementation can be applied by a kind of education governance to be successful.

This paper is the authors' point of view in an intensive collection and gathering of facts to answer some questions or queries to expose with the available educational theory that is best to apply in the present time. This query is relevant to satisfy a specific purpose which is to give a broader and concise discussion in building an academic institution in a specific government. This is considering the institution is either owned by the state or by visionaries is a community with the same purpose and mission. The conclusion and recommendation of this essay is based on the authors' personal views based from the statements of various authors and academicians. The discussion of theories is classified to comeup with clear understanding about societal development in the eyes of academicians' philosophical and educational exercise to contribute the existing academic implementation and practices.

This paper sought to compile different authors' statement to clearly discuss and give satisfaction to the questions relevant to application of an educational philosophy as societal opportunity and privilege. Questions that are to be justified are as follows:

1. What education is best to community opportunity and societal privilege?

2. What is the best educational schema that can be applied in building of an academic institution that envisions economic sustainability?

3. What are the characteristics of an educational system as anchored with the philosophy of education?

4. What educational structure or paradigm to be best suit societal opportunity and privilege?

\section{Methods}

The entire results of this essay are purely the extensive and careful selection of statements that contributes to theoretical implication. Additional and extra flowery words are discouraged to focus really to a direct and concise recommendation. Finally, this paper acknowledges the authors of various relevant materials used in this paper.

The statements and phrases that support the claims of each author on the topics are extracted in some online materials which are relevant to use because of its accessibility. All of the authors or philosopher's selections and consideration were based on the outline on the course as part of investigation.

In selecting appropriate materials, three aspects were to considered which include the popular theories applied in education; the vision covers educational opportunity and privilege; and finally a successful implementation in the economic sustainability of the government.

The result of this essay is a suggestive model and concept of an institution that the author believes as one of the best way to academic institutions in building a nation. This is also developing the personal educational beliefs of the author based on the gathered information as facts to all the claims.

\section{Literature Review}

The following papers and statements are compiled to discuss in relation to the queries that this essay sought to provide answer. The discussion is divided into three parts that includes education and its definition, collection of educational theories and economic implications of education based on various philosophers.

\subsection{Education by Virtue (Aristotle)}

In the understanding of a man that the philosophy of Aristotle is only applicable in a Greek ancient which is not true because even in some papers it is being studied to check its present application? The paper that checks ethical ideas of Aristotle's by gathering information and writings about his teachings give the ideas that in his philosophy a man needs to understand the relationship that exists between contact and pleasure which the noble acts to take place pleasure. Because man is rational in nature he has the potential to become good or bad. Therefore, Aristotle idea of education is 
an act of free will and an experiencing good education program can make a man good which the main idea of education is make man virtues. ${ }^{1}$

\subsection{Education and Justice (Plato)}

As to the point of view of Plato in the republic that an education is more on providing an improved religion and morality and less or simple teaching in music and gymnastic, a manlier strain of poetry, and greater harmony of the individual and the State ${ }^{2}$. Thus, this is belief of Plato, it is also being describe as the insight model that denies the very possibility of having transmission of ideas or bits of knowledge into the student's mental treasury which particularly teaching should take place in considering that students don't have any idea about the course ${ }^{3}$.

\subsection{Being Educated (Socrates)}

In the concepts discussed in one book that education must consider the learning experience of a child in how they are being thought according to standard. The standard is the perfect implementation and its must be follow, like the number of ration between teacher and students. This is because the philosophy is that once a student is not guided it can create a misconception that may lead to wrong knowledge. The students should be asked the right questions to learn ${ }^{4}$.

\subsection{Liberal Education (Oakeshott)}

In implementing educational philosophy in the present time is though liberal education is an old philosophical belief in education though O'Sullivan reviews the liberal education. As to its classical concepts, the radical revision to liberal education by Michael Oakeshott is examine to seek the similar delineation of the short essay of Spinoza which is "Tract on the Emendation of the Intellect (Tractatus de Intellectus Emendatione)" 5 that gives light to the ideal of education.

The major suggestion from the mentioned connection with Spinoza to Oakshott, is to incorporate the classical liberal ideal of education of a concept of enlightenment to philosophy of modesty that is also arguable because there is no specific answer what is modesty ${ }^{6}$. In general, the concept of educational ideal is like direction that can be followed not is very useful in the past and not in the modern world specifically in Europe then it is truly a human activity pursuit for the purpose of the university thus learning is a gift for all.

\subsection{Technologies of the Self (Foucault)}

The education based on the point of view of Foucault is the taking of oneself. Upon deep review of this theory made in Africa resulted to have come out a very important factors of education which this the past, present and future schooling, functions, development and prospects. This three important subject had been named to a course that are now well known as the politics, morality and communications thus it is being used to analyze the schooling and research as way of making human a person that is disciplined in a modern time ${ }^{7}$.

\subsection{Natural State of Education (Rousseau)}

A person is able to fulfill the needs of living in a society and remain in a natural state is the theory of natural man that brought the man to plan for his education that Rousseau believes contradicting to simply imparting only information to the learners ${ }^{8}$. Also Rousseau believes that Freedom is a very taskmaster that describe as an immigrant enters the US with joy because it is the land of freedom that no place so free that Freedom rings in this place?

\footnotetext{
Kabadayi, Talip (2013). Aristotle: On Virtue Education. Pamukkale University Journal of Social Sciences Institute, (14) 77-84.

Plato. (2002). The Republic. Purtugal, May 18.

Peters, R.S. (2010). The Concept of Education. London: Routledge and Kegan Paul Ltd., 103.

Peters, R.S. The Concept of Education, 12

Spinoza, Baruch. Tractatus de Intellectus Emendatione. Amsterdam, Dutch Republic: published posthumously, 1677.

Schueler, G.F. (1997). Why Modesty is a Virtue. Ethics: An International Journal of Social, Political, and Legal Philosophy, April, 107(3); and O'sullivan, Noël. (2011). The Place of Enlightenment in Michael Oakeshott's Conception of Liberal Education. POLITEJA. 3(15) 5-16.

7 Gallagher, Michael. (2013). Using Foucault in School Research: Thinking Beyond the Panopticon. Social Theory Applied, April 4. http://socialtheoryapplied.com/2013/04/04/using-foucault-in-school-research-thinking-beyond-the-panopticon/ (accessed October 8, 2016). Ansgar, Allen. (2014). Using Foucault in Education Research. British Educational Research Association. March 25, 2014. https://www.bera.ac.uk/researchers-resources/publications/using-foucault-in-education-research (accessed October 6, 2016).

8 Rawat, Khalid. Rousseau. August 20, 2008. http://pakphilosophy.blogspot.com/2008/08/rousseau.html (accessed October 11, 2016).

9 Otto, Stacy, and Virginia Worley.(2013). From the Editors. Journal of Philosophy and History of Education, vi-xii.
} 


\subsection{Liberal Education (Nussbaum)}

A liberal education philosophy is educating students to be the best in thinking critically and innovatively. Students are more likely best in reflecting novel problems, solving social and historical context problems and sophistically deliberate complex moral and social issues that make the person productive in an organization. A civilized and respected person that engaged in social and moral activity which is very crucial to collaborate in each public life. In this philosophy, students are exposed in ideas and perspectives' that deals with liberal arts courses which are humanities, history, mathematics, natural sciences, and social and behavioral sciences ${ }^{10}$ (Little, 2012).

\subsection{Banking Education (Freire)}

A traditional method of education or banking education is the term used by Friere in describing the transmission of knowledge from teacher to the students using curriculum. Liberating the system on education by means of offering programs that provides students the chance in developing ideas and realizing their ability as actors in changing the world around them. Therefore, Freire suggested that there is a possibility of merging freedom and responsibility in balancing the approach which be accounted in planning and programming the educational design ${ }^{11}$.

\subsection{Democracy and Education (Dewey)}

A criteria of analysis of Dewey focuses on three characteristics. These are observation, consideration and choice of alternative that should be natural outgrowth of existing conditions. As an overall to this paper that Dewey is not in favor to the idea of a fixed end as something to be "attained and possessed." ${ }^{12}$ Also Dewey is believing that teachers in building curriculum focuses around children's needs, concerns, and interests including food, clothing, shelter, need and care. Dewey was the first to introduce then child's concern and immediate needs as interests ${ }^{13}$.

\subsection{Transformative Education (IPP)}

Education in Jesuit or the Ignitians Pedagogy Philosophy introduces methods of education that transforms young people or students and to look themselves and other human beings is social system and structure in the community which is global and natural creation as a whole. These claims are really successful, the radical transformation has ultimate result not only the way people habitually think and act but also living in the world with competence, conscience and compassion for the greater good of all ${ }^{14}$.

\section{Discussion}

Theories of education even from the past are used to aid school implementers. These are being conceptualized to comeup with an appropriate implementation that authors of various study define theories of education. Educational philosophy and relates theories were describing to justify the claim of the author. The most basic is the Constructivism that illustrates how human learning occurs and its tendency to channel used the ideas of curriculum and instruction design in response to academic purpose based on the understanding of learning ${ }^{15}$. Also theory of education that defines that learning is a habit and this is accountable by habit that described learning is an observable action is called Behaviorist theory ${ }^{16}$. Piaget theory is also a belief of that the development of a child occurs through a continuous transformation of thought processes ${ }^{17}$. Multiple Intelligences (MI) Theory is also very popular that promotes the worth of the learners based on the innate talent than the acquired knowledge ${ }^{18}$. Right Brain vs. Left Brain theory in education used as the

10 Little, Daniel. (2012). Liberal Education. September 3, http://understandingsociety.blogspot.com/2012/09/liberal-education.html (accessed October 11, 2016).

11 Saleh, Salama Embark. (2013). Paulo Freire's Philosophy on Contemporary Education. Bulletin, English Department Faculty of Education, Agelat Zawia University, Zawia: University Bulletin, 91-111.

12 Suppes, Patrick. (1995). The Aims of Education. In Philosophy of Education, by Alven Neiman, 110-126. Urbana-Champaign: Philosophy of Education Society.

13 Otto, Stacy, and Virginia Worley. (2013). From the Editors. Journal of Philosophy and History of Education, vi-xii.

14 Jesuit Institute. (2014). Ignatian Pedagogy: An Abridged Version of the Document on Teaching and Learning in a Jesuit School. Ignatian Pedagogy - An Abridged Version, 1-12.

15 Taber, Keith S. (2011). Constructivism as Educational Theory: Contingency in Learning, and Optimally Guided Instruction. New York: Nova Science Publisher, Inc.

16 Standridge, M. (2002). Emerging Perspectives on Learning, Teaching, and Technology. AECT Publication. http://epltt.coe.uga.edu (accessed September 15, 2016).

17 Ojose, B. (2008). Applying Piaget's Theory of Cognitive Development to Mathematics Instruction. The Mathematics Educator, 26-30.

18 Howard-Jones, Paul A. (2009). Neuroscience, Learning and Technology. Becta, 1-39. Cercone, Kathleen. (2006). Mulitple Intelligence Theory. Information Science Publishing. 
opportunity to give importance to the both side of the brain for guidance ${ }^{19}$. Then finally, Communities of Practice (CoP) is a theory normally implemented in a groups of people that shares common concern and passion to learn interactive regularly to do better ${ }^{20}$.

\subsection{Educational Theory that Best on Societal Opportunity and Community Privilege}

The literature is very relevant based from the study of the authors from South Africa that gives justification to the purpose of this essay to address current problem to provide specific guidance in using communities of practice $(\mathrm{CoP})$ in higher educational institution on practical and theoretical knowledge. The study resulted to identify 15 criteria that out of those criteria 1 of it illustrates that "CoP acknowledge that learning is a function of the activity, context and culture" 21. This is very true because when the activity has an effect based on what are the context and culture learning takes place. Thus, the idea of the author about this results as the function of the three indicators that are; (1) activity which is the role of the institution to have it as societal advocacy to the community to make education an opportunity and a privilege that is set by the state; (2) context which is the state, the government or the community that that provides information about the need to support economic sustainability; and (3) culture which make the entire system to accepted to make the operations in place and practiced.

\subsection{Educational Philosophy to Build}

\subsubsection{Academic Institution that Envision Economic Sustainability}

The choice is very particular to a result that can help the community to have economic growth and sustainable support that can make the government more productive with quality improvements. The best educational philosophy that best to be used to meet the following goals is the transformation democratic way of education. Ignitians Pedagogy Philosophy is can be the best way to formulate academic excellence through transformation of the students by giving them the chance to choose among the different programs that can be offered. This programs are all based on a belief that everyone has a role in the community because of the acknowledging the stakeholders as part of the societal systems and structures that practiced habitually the competence, conscience and compassion for the greater good of all. Thus, when combined with the Dewey's Philosophy that in developing a program the need of a child whom to be the students is to consider as part of the community can result to providing the best for the stakeholders from different walks of life.

\subsection{Educational Structure Model on Community Opportunity and Societal Privilege}

The Figure 1 below is the prevailing model on the educational structure in building an academic institution that has the characterizes of a community that provides educational opportunity and a society that promotes privileges to member of the state or community. This is a simple analysis that the authors can proposed in building educational system and structure for the economic growth and sustainability.

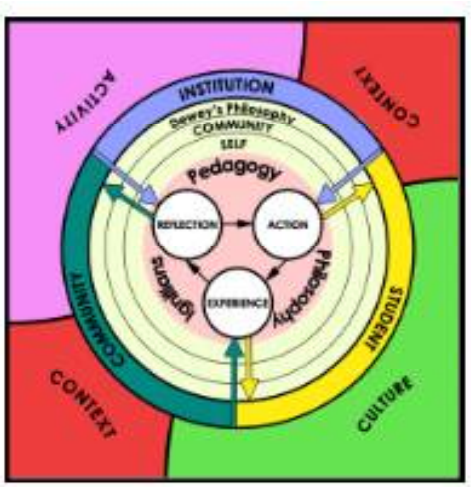

Figure 1: Educational Structure Model of Higher Academic Institution that Provides Community Opportunity and Societal Privilege

19 Daymut, Julie A. (2006). Right Brain vs. Left Brain - What's the Difference?. Super Duper® Publication. 202, 1-3.

20 Jakovljevic, Maria, Sheryl Buckley, and Melanie Bushney. (2013). Forming Communities Of Practice In Higher Education: A Theoritecal Perspective. Management, Knowledge and Learning International Conference. Zadar, Croetia: Active Citizen by Management, Knowledge Management \& Innovative, 1107-1119.

21 Jakovljevic, Maria, Sheryl Buckley, and Melanie Bushney. Forming communities of practice in higher education: a theoritecal perspective. 
This proposed structure model for educational implementation when given a chance to build an institution providing services in education. The community and the institution are involved in the activity to be used in the educational implementation to the student. The context whom to be the three major role player of the operations are to practice the vision sets by the organization to be a culture. The pedagogy to be used is the combination of the IPP and Dewey's philosophical characteristics to fully accomplished the main goal.

Cite this article as: N oel P. Sobejana (2021). Philosophy on Educational Accessibility: A n Opportunity and Societal Privileges. International Journal of Education and Teaching. 1(3), 1-6. doi: 10.51483/ IJEDT.1.3.2021.1-6. 